\title{
School Mapping and School System Planning for Economic Efficiency in a Developing Economy
}

\author{
Obasi, Kenneth K., Ph.D \\ Department of Educational Management \\ University Of Port Harcourt, Port Harcourt \\ Nigeria
}

\begin{abstract}
The thrust of this discourse was the challenges of economic rationality of school mapping to the planning of the education system especially in the period of economic quagmire. Firstly, it was viewed from the wider perspective of educational planning of which school mapping is a critical strategic part. Educational planning is a deliberate and systemic rational process of determining the goals and objectives and the relevant programmes for the growth and development of a society's education system. It is for the purpose of making the system more effective and efficient in addressing the needs and goals of the individual and the society at large. School mapping, as an integral part of the process entails the determination and rationalization of educational institutions of all types and levels. The fundamental reasons for school mapping are to guarantee access to education and to ensure an efficient school network and facilities utilization. Both reasons directly and indirectly promote economic rationality. One critical ingredient for school mapping is quality statistical data. School mapping is therefore a conscious systematic rational process of ensuring economic rationality and efficiency in the siting and rationalization of educational facilities. It is therefore recommended among others that the necessary legal provisions be made on the siting of new school and the rationalization of the existing ones. More professionals in mapping should be trained and the necessary equipment should be adequately provided.
\end{abstract}

\section{Introduction}

Education has continued to remain a critical factor in both human and national development. It occupies a central position in the dynamics of national development plans of countries across the globe, but more pronounced in the developing ones that are desperately struggling against the pains of ignorance, illiteracy, hunger, disease and marginalization. Whether viewed from investment or social perspective, education remains vital to the process of improving the productive capacity of individuals, and by extension, the socio-economic development of a nation. Ipso facto, the planning of education is imperative. This is founded on the strict adherence to the principle systemic integration in the educational planning process.

Educational planning is basically a decision making task that rationally analyses the prevailing situation, harnessing the available human and material resources for the attainment of predetermined goals in the future. One of the fundamental reasons for educational planning is economic efficiency in resource utilization. A very important and integral part of educational planning is SCHOOL MAPPING.

It is the systematic process of determining the future needs for education facilities at the different levels and types and their continuous rationalization within a definite geographical area. School mapping is periodically carried out to determine the existing school network, the distribution of educational facilities and to project into the future, the demands that would be made on them as a result of the dynamic nature of a given society. This is primarily with reference to population behavior and occupational changes. School mapping is carried out basically to ensure equity, access and economic efficiency.

However, the paper is specific on school mapping, with respect to economic rationality and efficiency in the siting and rationalization of educational facilities. This is against the backdrop of the prevailing global economic downturn which has emasculated many nations, particularly, the developing ones like Nigeria. Technically, this is economics of educational planning which has become imperative in the current economic reality. It is therefore a system's challenge that must be systematically addressed in order to make the education system efficiently functional. 


\section{Developing Nations}

Countries have been basically classified based on their levels of development; hence, we have the North and South. The countries that belong to the North described as developed from both socio-economic and political perspectives, characterized by modern production processes and high technology, very high literacy rate, gross domestic product (GDP), per capita income. Mbaskool (2018) described the developed countries those that enjoy certain high standards. Such countries, according to it have good infrastructures, stable economy with very high per capita income. The degree of development, industrialization and general standard of living for her citizens is very high. They generally have a stronger base of skilled workforce that earns decent wages which are generally higher than their counterparts in developing nations. The life expectancy of these countries are high. On the other side of the divide is the South which has been differently described as developing nations, less developed countries or Third world countries, even though the term "developing" is more positive and promising than the other two. However, used in general terms, they are under developed. Nigeria is a case in point. These countries share a lot of characteristics in common, which are mostly socio-economic and political in nature. They include very low gross domestic product (GDP), income per capita and standard of living. These manifest in high poverty level, illiteracy, disease, ignorance and hunger. Kuepper (2018) remarked that less economically developed countries exhibit the lowest indicators of socio-economic development. Referring to the United Nations standards, he stated that these countries have low incomes, human resource weakness and economic vulnerabilities that include weak and natural resources or population development.

Developmentally, the countries of the South are grossly backward. They have weak and vulnerable economies that are highly dependent on the North, and to a great extent, subservient to them, as they still depend on them for aids. The countries of the South, though politically sovereign, economically, they are not, as the always catch cold each time the countries of the sneeze. Based on some scholarly definitions, Kwat(2017), identified the proximate causes of underdevelopment as (i) poor per capita income (ii) capital deficiency (iii) unutilized potential for growth (iv) underutilized manpower and natural resources (v) poor base in the socio-economic determinants of development (vi) orthodox, inefficient and traditional techniques of production (vii) poor human development index.

Ipso facto, most of the developing nations that are domiciled in Africa, Asia and Latin America, continue to experience socio-economic crisis which significantly impede on the developmental indices, such as education, health and other social services. Also, international best practices in the planning and provision of education are grossly lacking, as the process is, many a time, fraught with over politicization, rather than based on sound rational consideration. This is evidenced in gross imbalance in the provision and distribution of educational facilities with respect to demographic distribution and geographic spread. This obviously, impact negatively on access, equity and efficiency in resource utilization.

\section{Education System Planning}

Though a relatively, new distinct area of enquiry, educational planning is at the heart of education systems across the globe, deliberately carried out to effectively and efficiently address the numerous issues, challenges, needs and problems confronting the systems vis-à-vis national developmental challenges. It is not surprising therefore that global institutions like UNESCO and WORLD BANK are relentlessly committing enormous human and material resources to educational planning especially through International Institute for Educational Planning (IIEP), through which the affiliate nations, particularly, the developing ones are substantially assisted in making their education systems strong, vibrant, responsive, functional, relevant and efficient.

Educational planning, basically, is planning applied to education at different levels and types. It is futuristic and a rational process because it entails the analyses of relevant data which are projected into the future in order to maximally takes advantage of the future. Educational planning is all about making rational decisions so as to adequately address educational needs, challenges and aspirations of a people. The explanation made by Coombs (1970) remains lucid and insightful. Educational planning, according to him, is certainly not a miracle for ailing educational systems. It is rather, the application of rational systematic analysis to the process of educational development for the purpose of making education more effective and efficient in responding to the needs and goals of its students and society. Educational planning involves the process of setting out in advance, strategies, policies, procedures, programmes and standards through which a set of educational goals and objectives can be achieved. It is detailed and systematic, and does not happen by chance (Butt, Hussain \& Rehman, 2016). 
Educational planning is ideologically neutral. The methodology and approaches it adopts are flexible and adaptable in response to varying and diverse situations and needs of different societies. It is sensitive to societal peculiarities. Today, as never before, the development of education is of prime importance to every country of the world. The swift and far reaching changes sweeping across the globe, the high rate of population growth, the exigencies of the fast developing economies, the widening gap between the North and South and the wealth of knowledge and technology available, are some of the factors confronting the developing nations. Consequently, the complexity and urgency of this task facing all peoples, if they are to reach the rate of economic and social development they aim at, has brought planning to the fore, as the best means of organizing the actions required rationally and systematically for the future (UNESCO, 1998).

Educational planning is therefore the formal process of making decisions for the future of both the individual beneficiaries and the society at large. It involves dealing with objectives to be realized, and selecting the right programmes and strategies. It also involves the determination and allocation of the resources required, and ensuring that plans are communicated to all concerned (Aggarwel \& Thakur, 2003). It is on this premise that Zaidi (2015) stated that planning, including education systems, is an exercise of resources optimization. It ensures the maximization of output within the given resources, so that the benefits are distributed more equitably among various section of the population. The uncertainties that surround the future as a result of environmental dynamism are predicted and significantly managed to the advantage of the society or organization through planning. This position was corroborated by UNESCO (1998) in its position, that educational planning is the intellectual anticipation of possible future situations, the selection of desirable objectives to be achieved and the determination of relevant actions that need to be taken in order to reach those objectives at a reasonable cost. It implies thinking about the future and trying to assume control over future events, by managing resources so that they cater the successful completion of the objectives set forth. Educational planning is therefore both a social instrument and a social process through which decisions are made on goals to be achieved, the specific actions and programmes to be implemented for the purpose of satisfying a society's educational needs (Obasi, 2012). One very critical component of educational planning is SCHOOL MAPPING. It deals basically with the determination and rationalization of educational institutions and other educational facilities.

\section{School Mapping}

As earlier stated, school mapping is an integral part of educational planning. It deals with the provision and rationalization of educational facilities, majorly from two angles: educational institutions at all levels and types and other school facilities. School mapping is the continuous process of determining, reviewing school network and educational facilities in order to ensure effectiveness and efficiency with educational goals and objectives of a definite geographical area. It is more of micro educational planning, considering the fact that it is more effectively carried out at state or local level. School mapping, to a large extent, combines with school plant planning. It involves the identification of the educational needs of a locality on a regular basis, through the assessment of the availability, condition and the utilization rate of educational facilities in that area. The aim of this exercise is to identify locations where existing and under-utilized facilities should be moved to, as well as where new ones are needed (Agabi, 1999).

School mapping entail the collection and analysis of demographic data and data on the existing educational facilities of a given area with the aim of making education more effective and efficient. It takes care of the future demands on education at various levels and types. UNESCO (2010) described school mapping as a set of techniques and procedures used to identify future needs in education at the local level and to plan for measures to be taken to meet them. It is a forward-looking and dynamic vision of what the education services, with their premises, teachers and equipment should be in the future so as to enable educational policy to be implemented. Whenever there is rational planning, the country's education plan, within a defined time frame, determines the quantitative and qualitative aims for education by the relevant authorities, considering the available resources. School mapping therefore, becomes the means of putting the aims of the plan into concrete shape on the ground so as to achieve educational aims as regards school children, wherever they may be and can be brought together (IIEP, 1982).

Ipso facto, school mapping is a strategic technique for the concretization of educational plans in order to address the educational needs of the society. The outcome of the process is the school map of a clearly defined geographical entity. 
Madumere (1989) remarked that school mapping goes beyond the identification of locations for the construction of schools, classrooms, laboratories and workshops. It is also a technique for the evaluation of use-efficiency, reorganization and redistribution of resources (physical and human), that are required for meeting the current and future needs of a society. It basically entails the setting up a school network that will meet in the most efficient and equitable way possible, the future demand for education.

School mapping, to a great extent, act as a bridge between the fixing of overall objectives and their translation into definite actions at the local level. It is bridge between the planning of education and its administration. It is a complex of operation that allows for the interaction between different levels of administration. School mapping does two basic things: (i) The rationalization of education resources (ii) Securing greater equality of educational opportunity. This implies seeking appropriate measures to guarantee equality in access to education and in teaching - learning conditions (UNESCO, 2010). The objectives of school mapping cut across the functions in micro planning, but principally, it is concerned with the problems that are associated with access and accessibility to the education system (school location). School mapping, a fundamental aspect of micro-planning involves basically the understanding of how the present educational services meet the needs of the local population groups (environmental diagnosis), and proposing better ways of distributing educational services or of diversifying their action programmes. School mapping and micro-planning ensure that global objectives are adapted to the particular characteristics of each region. This constitutes a formative stage in the planning process which entails applying the national plan at the regional and district levels. This is a great contribution to increasing the chances of attaining the national educational goals and objectives (IIEP, 1982). Hence, it seeks to satisfy effectiveness and to minimize costs as much as possible, while taking into account the overall educational objectives (Longe, 2000).

School mapping as an integral part of educational planning, involves carrying out a diagnostic inventory and utilization analysis of the school system as it affects the education needs of communities. It uses for its planning purpose, indicators such as participatory rates like enrolment rate at all the levels, radius per school and per child (the average distance a child covers to school) and the projection of future school requirements (Adiele, Obasi \& Ohia, 2017). School mapping is therefore a systematic rational process of determining the location, spacing and rationalization of educational institutions of various types and levels to ensure the setting up of a school network that will meet in the most efficient and equitable way possible, the future demands of education. The school map and the school plant are therefore the physical expression of a society's educational goals, objectives, programmes and projects. The determination of institutional network and the development of school plant must be the consequence of defined educational goals, objectives, programmes and projects. When the reverse is the case, it amounts to putting the cart before the horse (Obasi \& Ohia, 2017). The scope of school mapping covers the following specific areas for expansion and improvement of facilities: 1. Rationalization of existing facilities by the following: (i) shifting, closure or amalgamation of institutions (ii) optimum utilization of teaching and nonteaching staff (ii) optimum utilization of buildings, equipment, furniture etc. 2. Provision of new or additional facilities by the following: (i) opening of new schools or upgrading of existing ones (ii) providing additional teaching and non-teaching staff (iii) providing new or additional buildings, furniture and equipment in institutions (Sabir, 2013).

\section{School Mapping and Educational Statistics}

Planning generally, to a very large extent, thrives on statistical data. The rationality of the planning process is based on the simple fact that it makes use of logical reasoning founded on factual evidence (data). Quality data give credibility to planning. To that extent, the quality of educational planning significantly depends on the quality of data at its disposal. The importance of data in terms of quality and quantity cannot be over emphasized. Educational statistics represents numerical information that is organized and presented in relation to each other to convey meaningful messages on the state of educational development and the performance in a given situation. Statistics are facts that consist of numbers obtained from the analysis of information (The Free Dictionary, 2015). Statistics provides the fundamental and rational basis for any meaningful planning. It guarantees effectiveness, and efficiency. The management of statistics involves the collection, organization, analysis, interpretation and presentation of numerical information. Educational planning, and by extension, school mapping, relies very much on statistical data. No meaningful school mapping can be carried out without realistic, reliable and timely data. 
To buttress this point, Akinwumiju (1995), pointed out that educational planning process involves the collection and analysis of quantitative and qualitative information concerning the educational system and also, related statistics, to serve as a basis for policy decisions regarding the future development of education.

Educational statistics is critical to school mapping since it deals with institutional network at all the levels and types of education in order to guarantee access and rationality. To that extent, demographic data are imperative. It requires adequate information on the structure and behaviour of the population of any given geographical area under review.

The demographic data require the determination of the distribution of the population by age and sex, so as to know the school-age population. Also to be determined for effective use is the rate at which the population grows, the migration rate and the death rate. Akinwumiju (1995) identified other data that are relevant to effective school mapping. They include data on school buildings and equipment, teaching and non-teaching staff, classes which should include number of arms/classes by grades, data on cost of expenditure (capital and recurrent), students/pupils by sex, age and grade. The importance of statistical data in school mapping was also highlighted by Arinze (1991), when he remarked that demographic data are critical in estimating the school age population of a particular locality at a future date. This is to enable educational planners to determine whether or not an educational institution in that area will have adequate clientele.

\section{School Mapping and Economic Efficiency in Education System Planning}

One of the fundamental reasons for the planning of education is to ensure economic rationality, efficiency in the utilization of education resources (human and material) and the minimization wastages. This position was buttressed by Agabi (1999) as he remarked that the first rationale for the planning of education for the optimum allocation and utilization of resources available, to satisfy the society's numerous and competing needs, including education, are not only scare, but subject to varied uses, put pressure on the need to be rational in the allocation of these resources is simply as a result of resource scarcity subject to needs. The simple fact is that the resources are meant to achieve the highest benefits. Consequently, it can easily be concluded that without the most fundamental economic problems of scarcity and the need for choice, there would have been no need for planning.

School mapping, as an integral part of planning, is therefore one of the strategic instruments to achieve some economic rationality and efficiency in the determination of school network and rationalization in an educational system through micro planning. The two major objectives of school mapping which are equity in access and efficiency in the siting and rationalization of educational facilities, directly and indirectly, ensure economic efficiency. When schools, especially primary and secondary are not adequately mapped, to guarantee access based on population distribution, many children of school age will be denied access which will consequently result in the loss of potential manpower to the economy. As a result of poor school network, some pupils/students who manage to enroll may trek long distances to school, thereby creating room for poor academic performance and consequently, truancy, repetition and withdrawals. This is a veritable potential scenario for wastages in the school system. Such an ugly situation may also lead to high transportation cost which is an avoidable addition to private cost for acquiring education. This is one of the major contributory variables to out-of-school children in the developing nations, which is a potential threat to socio-economic development.

The other side of the coin in school mapping is the deliberate effort to ensure efficiency in school location and rationalization. This aspect has a more direct implication because it ensures that educational institutions are located where they can be optimally utilized by the clientele. This is based on the fact that a society's population is dynamic, both in structure and behaviour. The continuous rationalization of educational institutions and facilities is in line with demographic changes that are constantly experienced in the society. On the strength of this fact, Arinze (1991) pointed out that one basic reason for school mapping is to make sure that educational resources are maximally utilized and educational institutions are efficiently run. Hence, the size of the school, utilization rates of educational resources must be properly considered

The present day economic quagmire starring everybody in the face across the globe, and worse still in the Nigerian State, is a harsh reminder of the invaluable role that school mapping plays in the economic equation of educational planning. Economic recession is a period of low productivity, high unemployment rate and inflation rate, with the attendant significant dip in the Gross Domestic Product (GDP). Consequently, education which is more of a social service, especially at the first two levels, must be planned in strict compliance with economic rationality which is one of the cardinal points of school mapping. 


\section{Conclusion}

Educational planning is a deliberate, systematic rational process of making a society's education system address the educational needs, challenges and aspirations, by ensuring the use of available human and material resources in the most effective and efficient manner. One of the strategies adopted by educational planning to guarantee the attainment of these objectives is school mapping, which aims at ensuring high level access to education and the efficient provision and utilization of educational facilities. School mapping as an aspect of educational planning, is therefore a strategic instrument for economic rationality. It is an imperative in the process of educational planning especially in this period of economic downturn.

\section{Recommendations}

Based on the above analytical discourse, the following recommendations are put forward:

- The Ministry of Education and the relevant bodies should provide a comprehensive legal framework to guide the siting of new schools and the rationalization of the existing ones.

- There should be policy provisions on the frequency with which schools mapping should be carried out.

- Educational planners should work in synergy with the relevant bodies for the provision of the relevant data in their right quantities and qualities.

- As a result of the technical nature of school mapping, more manpower should be specially trained in this area and the necessary equipment for mapping provided.

\section{References}

Adiele, E., Obasi, K. K. \& Ohia, A. N. (2017). Fundamentals of educational planning. Port Harcourt: Harcy Publications

Agabi, O. G. (1999).Introducing educational planning.Port Harcourt: InternationalCenter for Educational Services.

Aggarwal, Y. P. \& Thakur, R. S. (200030). Concepts and terms in educational planning: A guidebook. New Delhi: Operations Research and Systems Management Unit, National Institute of Educational Planning and Administration.

Akinwumiju, A. (1995). Educational planning statistics.Ibadan: Faculty of Education, University of Ibadan.

Arinze, F. O. M. (1991). School mapping: A basic function of educational planning. In C. N. Uwazurike (Ed.) Educational planning and national development: A Nigerian perspective. (251-267). Awka: Mekslink.

Butt,A., Hussain, M. \& Rehman, S. (2016). Emergence of educational planning. Retrieved from: https://www.slideshare.net/shafiqurrehman526/educational-planning-56831868

Coombs, P. H. (1970). What is educational planning? Paris: UNESCO International Institute for Educational Planning.

International Institute for Educational Planning (1982). Intensive training course on micro-planning and school mapping. Paris: UNESCO

Kuepper, J. (2018). What is a developing country? Retrieved from: https://www.thebalance.com/what-is-a-delopingcountry-1978982

Kwat, N. (2017). Underdeveloped countries: meaning and classification of definitions. Retrieved from: www.economicsdiscussion.net/underdeveloped-countries/underdeveloped-countries-meaning-and-classification

Longe, R. S. (2000). Introduction to educational planning. Ibadan: Department of Educational Management.

Madumere, S. C. (1989). School mapping as a tool for rationalization of institutional network of schools. Ikeja: Joja Educational Research and Publishers.

Mbaskool (2018). Developed economy. Retrieved from: www.mbaskool.com/business-concepts/finance-accountingeconomics-terms/13336-developed-economy.html\#null

Sabir, M. M. (2013). School mapping in the light of education reforms in Pakistan. American Journal of Educational Research. 1(8), pp 279-282.

Obasi, K. K. (2012). The concept of planning. In J. D. Asodike, L. E. S. Kaegon, O. E. Oluwolu \& N. Amadike (Eds.) Educational planning and supervision: An introductory text. (1-19). Port Harcourt: Infomedia Grafik

Obasi, K. K. \& Ohia, A. N. (2017). Educational planning: the basics. In A. K. Okorosayo-Orubite, C. N. Olele, O. G. Kemjika, N. M. Abraham \& G. Adekola (Eds.) Introduction to education. (173-199). Port Harcourt: Faculty of Education, University of Port Harcourt.

The Free Dictionary (2015). Statistics. Retrieved from http://www.thefreedictionary.com

UNESCO (1998). Elements of educational planning. Paris: UNESCO

Zaidi, S. M. I. (2015). Methodology of planning for education. Retrieved from file:///E:/methodology\%20of20planning\%20for\%20eduation.htm 